\title{
Research on a Method of Evaluating Fuel Efficiency during Traveling and Driving for Head-feeding Combine Harvesters
}

\author{
Hirofumi YAMASAKI*, Mitsuhiro HORIO and Kohichi FUJITA \\ Institute of Agricultural Machinery, National Agriculture and Food Research Organization, Saitama, \\ Japan
}

\begin{abstract}
We studied the impacts of soil surface hardness and increased machinery body mass by the harvested crop relative to the fuel efficiency during traveling and driving for head-feeding combine harvesters. The fuel efficiency during traveling and driving increased with softness of the soil, showing a strong correlation with the index of hardness indicated in the Yamanaka model soil penetrometer. The index of hardness realizing fuel efficiency equivalent to traveling on the road was about $23 \mathrm{~mm}$. Based on the fuel efficiency and index of hardness obtained in the testing, a relational expression between the index of hardness and fuel efficiency of the machinery provided for the testing was then figured out, thereby making it possible to correct the fuel efficiency during traveling and driving under any soil conditions. We also confirmed that fuel efficiency during traveling and driving increased with the mass of rough rice in the grain tank. We devised methods of testing and evaluating the fuel efficiency during traveling and driving, by correcting such conditions so as to make a fair comparison among different models.
\end{abstract}

Discipline: Agricultural Engineering

Additional key words: fuel efficiency, head-feeding combine harvester, soil moisture weight percentage, soil surface hardness, Yamanaka model soil penetrometer

\section{Introduction}

In Japan, automakers have been required to satisfy and achieve performance exceeding a standard level of fuel efficiency after the Act on the Rational Use of Energy was enacted in 1979; accordingly, significant technical advances have been made to improve the fuel efficiency of automobiles. And since the Kyoto Protocol took effect in 2005, the reduction of greenhouse gas emissions has recently been urgently required in order to take measures against global warming. Under such circumstances, standards and regulations on fuel efficiency would greatly contribute to measures against global warming, as higher fuel efficiency directly results in the reduction of greenhouse gas emissions. The enactment of such standards and regulations on automobiles is not limited to Japan, as evidenced by similar enactment in the US and EU, as well as recently in Asian countries.

In the case of automobiles, regulations on fuel efficiency and gas emissions are enforced by measuring both the fuel efficiency and gas emission of a vehicle based on the actual driving speed patterns designated in respective countries. Such regulations on fuel efficiency still do not exist for agricultural machinery in Japan, but regulations on gas emissions are also enforced in the field of agricultural machinery. Unlike the case of automobiles, regulations are enforced for emissions from engines mounted on the machinery, instead of emissions from the whole vehicle. The measurement of gas emission entails applying a fixed load pattern to the engine while controlling the engine speed during the measurement process. In the case of agricultural machinery as with automobiles, measuring fuel efficiency at the same time as gas emission measurement, for which regulations are already enforced, could be advantageous in terms of both testing repeatability as well as time and labor. However, the load patterns in the 8-Mode Method (Testing Cycle C1) and NRTC Method (JIS B 8008-4: 2009, JIS B 800811: 2008) currently applied in the measurement of gas

*Corresponding author: h_yamasaki@affrc.go.jp

Received 25 March 2019; accepted 28 November 2019. 
emissions from agricultural machinery equipped with diesel engines are designed in view of diesel-powered special motor vehicles as a whole including construction machinery. Consequently, the operating environment for such design is quite different from that for agricultural machinery, and these patterns very unlike in-field working. Differences between the actual operational status of riding tractors and the 8-Mode Method have been reported (Seki et al. 2006), meaning that the ongoing testing methods for gas emissions are not applicable in testing the fuel efficiency of agricultural machinery, thereby making it necessary to establish methodology for measuring the fuel efficiency of agricultural machinery.

Based on the development of fuel efficiency evaluation methods for riding tractors and grain dryers by considering actual operational status, "Labeling of the Certificate on Energy Saving Performance of Agricultural Machinery" has been implemented in Japan since 2014 in order to reduce $\mathrm{CO} 2$ emissions. The certificate is given to agricultural machinery models that satisfy a fixed level of fuel efficiency as energy saving machinery, and manufacturers are working with technical development to improve fuel efficiency. Similar to other types of farm machinery, implementing fuel efficiency evaluation is also required for head-feeding combine harvesters. This is due to the high unit fuel consumption per machinery operating time and the number of machinery units currently in use. Head-feeding combine harvesters are widely used in Japan and is spreading to other Asian countries as well. The full tank method (i.e., filling the fuel tank before and after harvest work) has been conventionally used to evaluate the fuel efficiency of head-feeding combine harvesters (Suzuki et al. 1980). This method can be considered a fact-based testing method as field testing is actually conducted, but repeatability of the data obtained is poor due to differences in fuel efficiency performance depending on the crop and field conditions at the time of testing. Headfeeding combine harvesters incorporate a tank to store paddy rice. Such machinery repeats "harvesting" and "a $90^{\circ}$ turn," and after a full amount of grain is stored, and these harvesters "transport" and "discharge paddy rice." Each of these work structures for "harvesting," "making a $90^{\circ}$ turn," "transport," and "paddy rice discharge" has a different fuel efficiency characteristic, and each has factors that affect fuel efficiency. In other words, if we perform the measurement by mixing each element as in the case of the full tank method, it is difficult to determine what has been affected and to what extent. Therefore, based on the work structure of head-feeding combine harvesters, we considered that fuel efficiency consists of five detailed components defined as "fuel efficiency during traveling and driving," "fuel efficiency during reaping, threshing and sorting," "fuel efficiency during a $90^{\circ}$ turn," "fuel efficiency during transport," and "fuel efficiency during paddy rice discharge" (Fig. 1). "Fuel efficiency during traveling and driving" is the fuel efficiency during unloaded traveling while reaping, threshing, and sorting parts are activated. "Fuel efficiency during reaping, threshing and sorting" is a deduction of "fuel efficiency during traveling and driving" from the fuel efficiency required for a harvest of paddy rice (fuel efficiency during harvesting). "Fuel efficiency during a $90^{\circ}$ turn" and "fuel efficiency during paddy rice discharge" are measured to obtain fuel efficiencies required for making a $90^{\circ}$ turn and paddy rice discharge, respectively. "Fuel efficiency during transport" is "fuel efficiency during traveling and driving" at the maximum speed. In this research, we focus on fuel efficiency during traveling and driving. It has been empirically known that soil surface hardness in the field where the harvest was carried out and the increase in self-weight accompanying the harvesting have an effect on "fuel efficiency during driving."

In previous studies on the fuel efficiency of headfeeding combine harvesters, Sakai et al. (1988) calculated the fuel consumption per unit area required for paddy rice harvesting in four categories: "load by crop feeding," "load by reaping, threshing and sorting parts," "load by traveling," and "load by engine without working." D. C. Baruah et al. (2005a) reported an energy demand model for each component of conventional combine harvesters, and conducted multiple regression analysis based on the results of harvesting tests with paddy rice and wheat using seven conventional combine harvesters (engine power: $29.0 \mathrm{~kW}-55.0 \mathrm{~kW}$, drive system: wheel). Baruah et al. (2005b) also associated the developed models. In the associated models, "frictional resistance at the horizontal

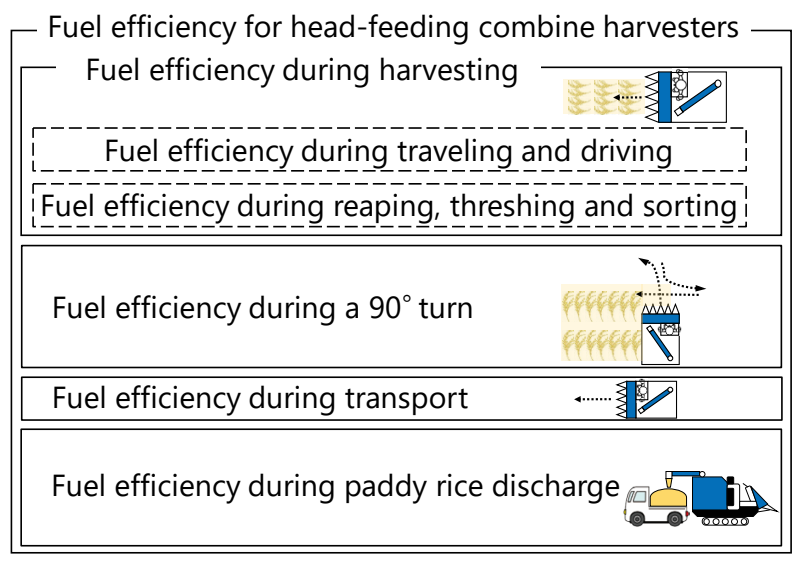

Fig. 1. Fuel efficiency components of head-feeding combine harvesters 
bearing surface of a reciprocating knife due to its selfweight," "impact of the threshing cylinder on crop mass," and "tractive resistance due to self-weight of the combine harvester associated with parameters regarding the center of gravity position, wheel and soil cone index" were selected as the model coefficients.

However, there has been no detailed study on the effect of soil surface hardness and an increase in selfweight on the fuel efficiency of head-feeding combine harvesters. In this research, we demonstrate the impacts of soil surface hardness and increased machinery body mass by the harvested crop relative to fuel efficiency during traveling and driving. This is intended to devise a correction method for a fair methodology of comparison among different models regardless of testing conditions, and we report on it. In this report, we consider hourly fuel consumption as one of the indexes of fuel efficiency.

\section{Testing method and measurement items}

\section{Impact of soil surface hardness on fuel efficiency during traveling and driving}

We used four models of 4-row type head-feeding combine harvesters (Units A, B, C, and D) made by Japanese manufacturers for the testing. The engine speed is set to the rated revolution output, with three testing sections set at $70 \%, 80 \%$, and $90 \%$ of the maximum speed for the traveling speed, and the test is conducted with the grain tank being empty. Table 1 lists the specifications of the tested combine harvesters. We selected places in many different conditions of postharvest paddy rice fields, which were also required not to be rutty, in order for us to obtain testing results under different field conditions. There, we activated the reaping, threshing and sorting parts of the respective models for unloaded traveling, and also performed measurements of the same perspective on a concrete surface. We prepared a test section of about $30 \mathrm{~m}$, of which the latter $20 \mathrm{~m}$ was designated as the measurement section. Figure 2 shows an overview of this measurement test. The skid ratio, fuel flow, fuel temperature, time of passing through each test section, soil surface hardness, and surface soil moisture weight percentage are set as the measurement items. The soil texture of the testing field in accordance with the ISSS (International Society of Soil Science) Method was $\mathrm{SiC}$ for Unit A, SiC and L for Units B and C, and $\mathrm{HC}, \mathrm{LiC}$ for Unit D, respectively.

The skid ratio was calculated based on the crawler length, by measuring the traveling distance through five circulations of the crawler. Fuel flow and fuel temperature were measured by using a fuel flow gauge (ONOSOKKI, FP-2240HA) to obtain the unit fuel consumption per time (reduced property at $15^{\circ} \mathrm{C}$ ). The time of passing through each test section was measured by setting reflecting plates (OMRON, E39-R1) at the start and end of the measurement section, while utilizing a photoelectric sensor (OMRON, E3S-AR16) and a digital timer (OMRON, H5CX-L8D-N) mounted on the body of the

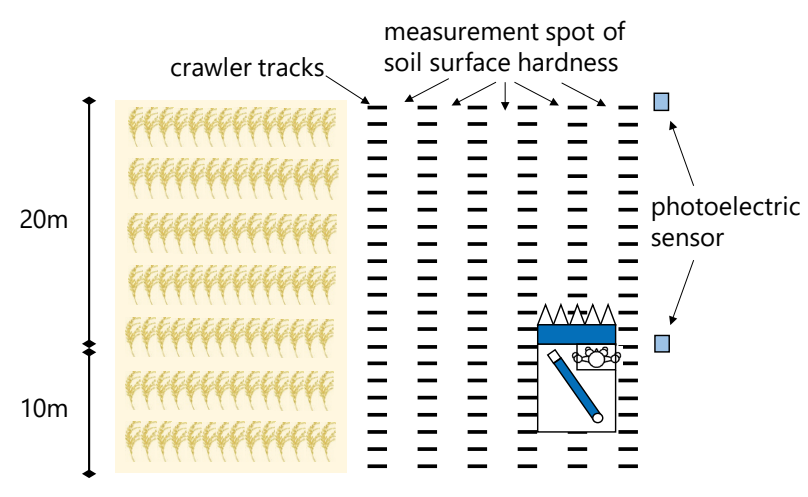

Fig. 2. Overview of the measurement test

Table 1. Specifications of tested combine harvesters

\begin{tabular}{lcccc}
\hline \hline & Unit A & Unit B & Unit C & Unit D \\
\hline Rated Power (kW) & 37.1 & 34.8 & 34.5 & 55.4 \\
Rated Revolution (rpm) & 2,800 & 2,600 & 2,700 & 2,600 \\
\hline Maximum Velocity (m/s) & 1.55 & 1.46 & 1.43 & 1.63 \\
Weight (kg) & 2,530 & 2,350 & 2,290 & 3,575 \\
Fuel & \multicolumn{4}{c}{ diesel } \\
Drive System & 450 & 450 & 470 \\
Crawler Width (mm) & 1,525 & 1,570 & 1,525 & 1,670 \\
Ground Contact Length (mm) & 18.1 & 16.2 & 15.7 \\
\hline Average Ground Contact Pressure (kPa) & 23.3 \\
\hline * True values measured on a concrete surface, with the reaping, threshing, and sorting \\
parts of the respective models activated for unloaded traveling
\end{tabular}


harvester. To obtain the surface soil moisture weight percentage, we used a soil sampler (DAIKI RIKA KOGYO, DIK-1600) by attaching a sampling tube (DAIKI RIKA KOGYO, DIK-1801; inner diameter of 50 $\mathrm{mm}$, height of $51 \mathrm{~mm}$, internal space of $100 \mathrm{~mL}$ ) for picking up the testing sample from a surface layer of 50 $\mathrm{mm}$ in depth, and then applied the oven method (at $110^{\circ}$ Cfor $24 \mathrm{~h}$ ) (Japanese Society of Agricultural Machinery 1977a). The soil surface hardness was measured on flat ground without crawler tracks, which should also be at the center of both inter-row space and inter-hill space. There, straw on the surface was removed, but the surface soil was not stripped. A Yamanaka model soil penetrometer (DAIKI RIKA KOGYO, Push-Cone DIK-5553, Fig. 3) was used for the measurement, following the Standard Methods for Soil Analysis and Measurement (Commission for Standard Methods for Soil Analysis and Measurement 2003). At the same time, the soil subsidence of the surface soil at $294 \mathrm{~N}$ of normal load with a small rectangular plate (bottom surface: 25 $\mathrm{mm} \times 100 \mathrm{~mm})$ attached to a soil penetrometer YAMAZAKI SEIKI SEISAKUJO, Model SR-2, Fig. 4), hereafter referred to as "small rectangular plate subsidence," was measured altogether (Japanese Society of Agricultural Machinery 1977b). The manufacturer of the Model SR-2 we used for the measurement no longer exists, but an equivalent measurement is possible by using the Model SR-2 currently commercialized by a

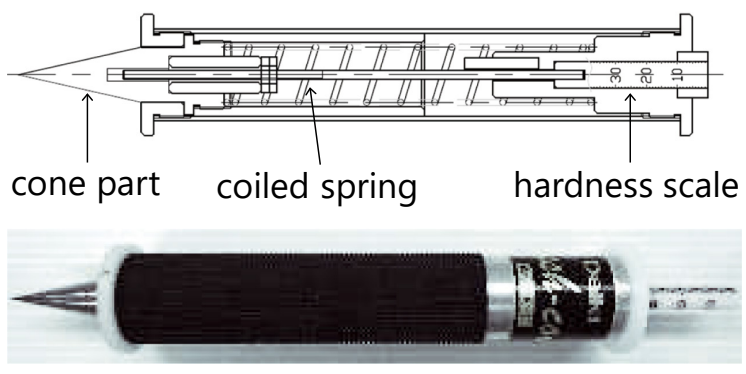

Fig. 3. Yamanaka model soil penetrometer Above: a schematic view provided by DAIKI RIKA KOGYO

Below: photograph

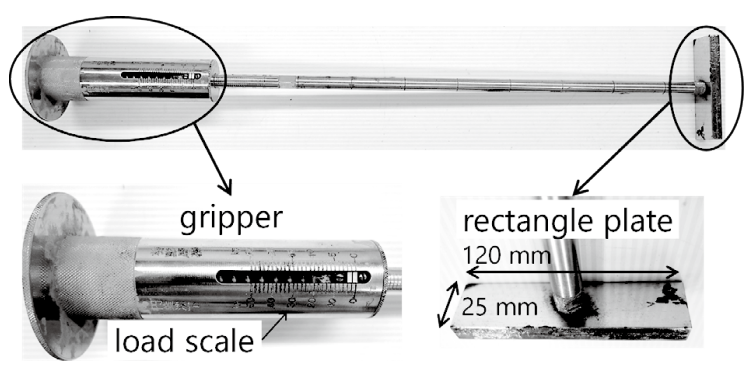

Fig. 4. Model SR-2 soil penetrometer different manufacturer. The cone part of the Yamanaka model soil penetrometer (with height of $40 \mathrm{~mm}$, bottom diameter of $18 \mathrm{~mm}$, and apex angle of $25^{\circ} 20^{\prime}$ ) was pressed into the ground at a right angle by using the coil spring installed inside. The spring constant of the coil spring is 8 $\mathrm{kg} / 40 \mathrm{~mm}$, and the resistance value at that time is expressed by the displacement of the spring as an index of hardness (mm). Based on a report by Yamanaka et al. (1962), we can use the formula below to express the bearing strength $P(\mathrm{MPa})$ of the cross section of the cone part of the Yamanaka model soil penetrometer that we applied into the ground, using index of hardness $X(\mathrm{~mm})$ and gravity acceleration $\mathrm{G}$ (constant).

$$
P=\frac{320 \times \mathrm{G} \times X}{81 \pi(40-X)^{2}}
$$

\section{Impact of increased machinery body mass by the harvested crop relative to fuel efficiency during traveling and driving}

A 4-row model head-feeding combine harvester (Unit A in Table 1) was provided. The engine speed was set to the rated revolution output, with three testing sections set at $70 \%, 80 \%$, and $90 \%$ of the maximum speed for the traveling speed to conduct the test. We carried out unloaded traveling on a concrete surface while activating the reaping, threshing and sorting parts of the machinery, with the grain tank being fully loaded $(631 \mathrm{~kg})$ with rough rice. We then varied the mass of rough rice (hereafter referred to as "grain mass") in the grain tank to $529,332,233$ and $0 \mathrm{~kg}$, in order to continue the measurement likewise. We prepared a test section of about $30 \mathrm{~m}$, of which the latter $20 \mathrm{~m}$ was designated as the measurement section. The skid ratio, fuel flow, fuel temperature, and time of passing through each test section are set as the measurement items.

As for the means of measurement, we followed the same method as described in Section 1.

\section{Results}

\section{Impact of soil surface hardness relative to fuel efficiency during traveling and driving}

(1) Characteristics of Yamanaka model soil penetrometer

Figure 5 shows the relation between small rectangular plate subsidence $Z$ and measured value $X$ by the Yamanaka model soil penetrometer (hereafter referred to as "index of hardness"). Soil classification criteria for the ease of harvest work by a head-feeding combine harvester was set at $20 \mathrm{~mm}$ and below subsidence on a footprint when the minimum ground clearance of the body was low (Japanese Society of Farm Work 
Research 1985), and at $30 \mathrm{~mm}$ and below for small rectangular plate subsidence, as it was reported to be about 1.5 times (at load of $30 \mathrm{~kg}$ ) the subsidence on a footprint (Kanesu et al. 1966a). We conducted testing for this report in fields satisfying this range.

When the soil is softer, the index of hardness became smaller whereas the small rectangular plate subsidence was found to be larger. The small rectangular plate subsidence and index of hardness were in a logarithmic relation; we found that change in the index of hardness on a soft soil field was limited despite the higher value of small rectangular plate subsidence, whereas the fluctuation of small rectangular plate subsidence was limited on a hard soil field, also despite the increase in the index of hardness.

Figure 6 shows the relation between soil moisture

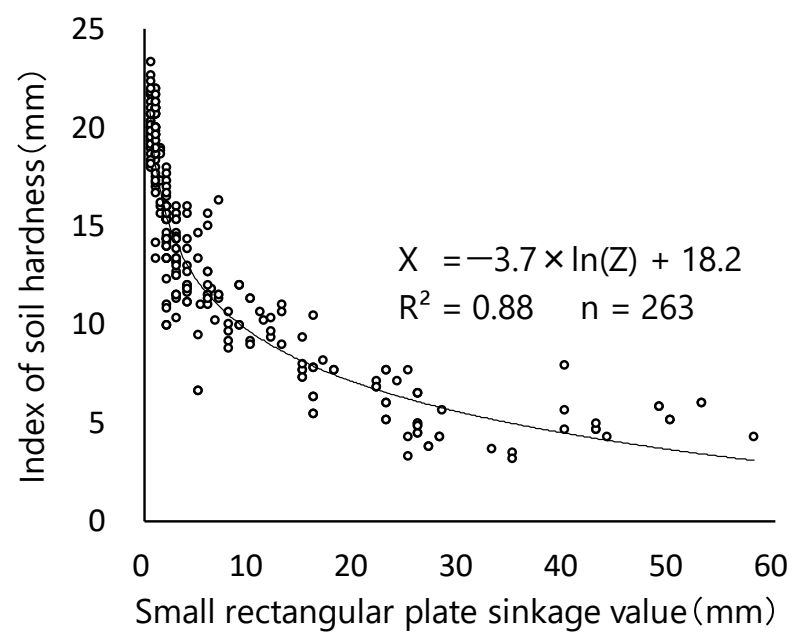

Fig. 5. Relation between small rectangular plate subsidence and index of hardness

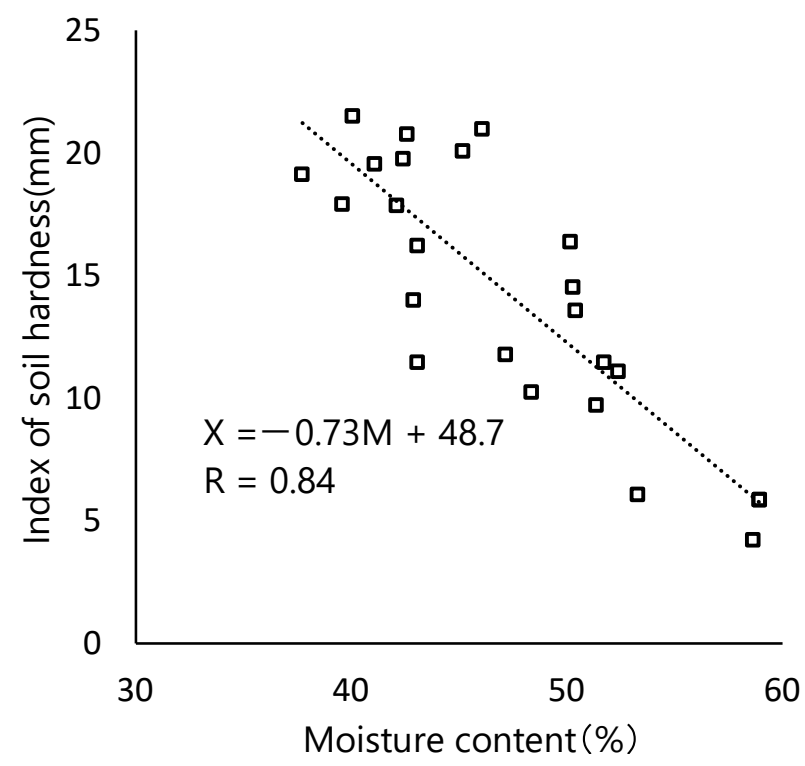

Fig. 6. Relation between soil moisture content and index of hardness weight percentage $\mathrm{M}$ and index of hardness $X(\mathrm{~mm})$. Upon finding a decline in the soil moisture weight percentage, we confirmed harder soil and an increase in the index of hardness, which suggested a strong correlation.

(2) Relation between index of hardness and fuel efficiency during traveling and driving

The hourly fuel consumption was confirmed to increase in response to an increase in the traveling speed (Fig. 7); therefore, we obtained a regression formula of traveling speed and hourly fuel consumption for each test section via the least squares method to eventually calculate the hourly fuel consumption at $80 \%$ of the maximum speed. Here, we did not apply the direct results of the test sections where testing was carried out targeting $80 \%$ of the maximum speed, as it was impossible for us to adjust the actual traveling speed exactly at $80 \%$ of the

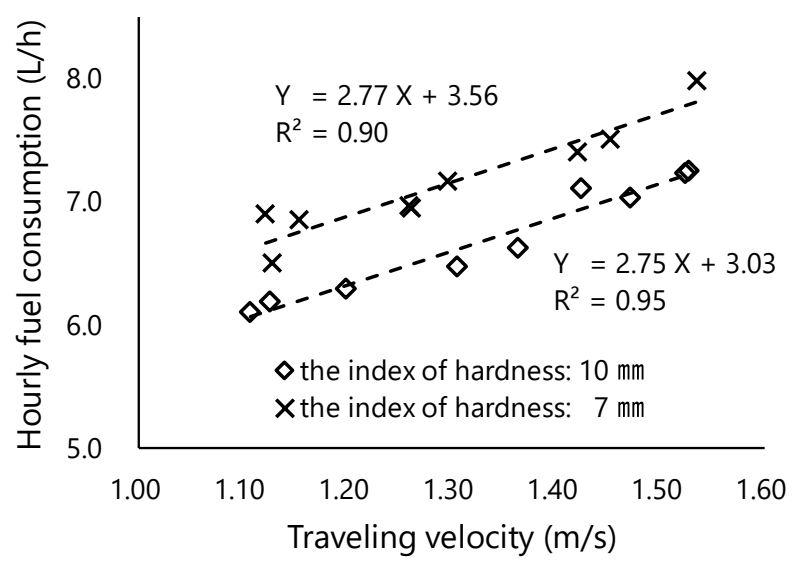

Fig. 7. Relation between traveling velocity and hourly fuel consumption

An instance; soil texture: $\mathrm{SiC}$, tested combine harvester: Unit A

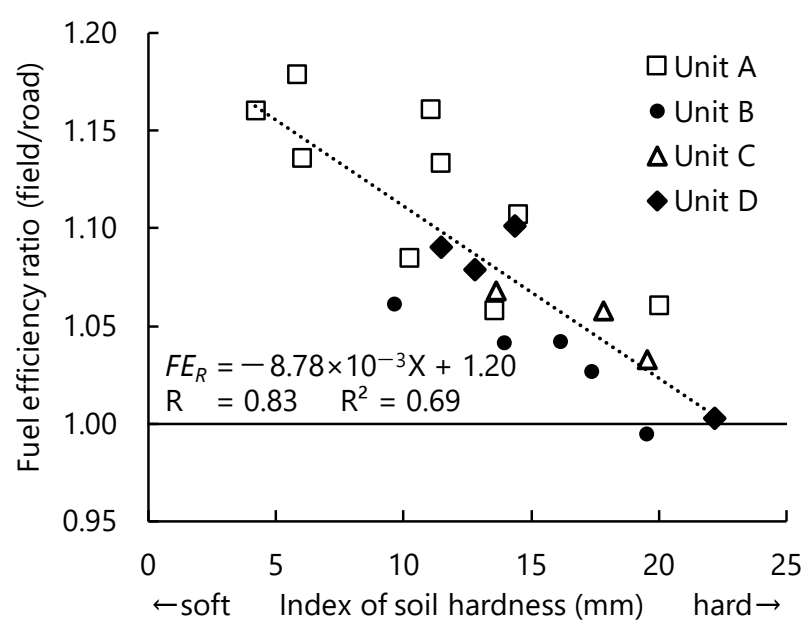

Fig. 8. Relation between index of hardness and fuel efficiency ratio 


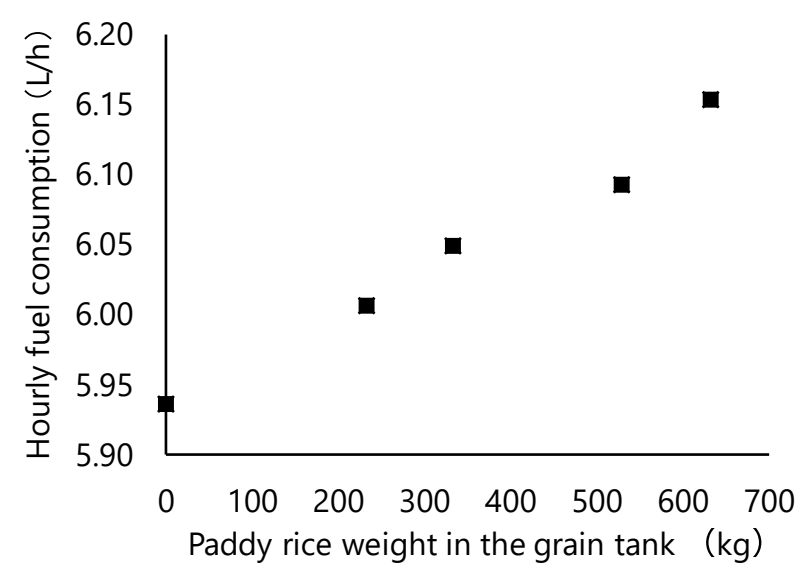

Fig. 9. Relation between calculated hourly fuel consumption at $80 \%$ of the maximum speed and grain mass

maximum speed in all the test sections. Figure 8 shows the relation between the value dividing the hourly fuel consumption in each field by the one on the road (hereafter referred to as "fuel efficiency ratio") and the index of hardness in each field. The fuel efficiency ratio tended to increase as the index of hardness declines. This presumably resulted from the increased resistance for traveling due to soft soil. We noted a strong correlation between index of hardness $X(\mathrm{~mm})$ and fuel efficiency ratio $\mathrm{FE}_{\mathrm{R}}$, and as a result of the regression formula that we obtained via the least squares method, we obtained an index of hardness of about $23 \mathrm{~mm}$ in realizing fuel efficiency equivalent to traveling on the road.

We did not consider the impact of skidding in this testing as no such phenomenon was observed.

\section{Impact of increase in machinery body mass by the harvested crop on fuel efficiency during traveling and driving}

In the same way as in the testing described in the previous section, we obtained a regression formula of traveling speed and fuel efficiency during traveling and driving for each test section via the least squares method to eventually calculate the hourly fuel consumption at $80 \%$ of the maximum speed. Figure 9 shows the relation between the calculated hourly fuel consumption at every test section and the grain mass. With regard to an increase in the grain mass, we confirmed an increase in the fuel efficiency during traveling and driving.

\section{Discussions}

\section{Impact of soil surface hardness on fuel efficiency during traveling and driving}

(1) Characteristics of Yamanaka model soil penetrometer As shown in Figure 6, the soil in paddy fields dries and soft soil becomes harder as the harvest time approaches. In order to ensure the quality of paddy rice, farmers refrain from harvesting before harvest time as much as possible. Thus, fuel efficiency should be measured on a somewhat dry hard field. We decided to use the index of hardness as the index for soil conditions, as it more clearly shows the difference in values on hard fields as compared with small rectangular plate subsidence, which has been conventionally applied to soil conditions for head-feeding combine harvesters, and also because measurement can be done easier and in a shorter time.

We also considered the relation between the soil moisture weight percentage and index of hardness as described here. By conducting experiments using a model, Ezaki et al. (1982) noted the probability of approximating the relation between subsidence by headfeeding combine harvester $Z^{\prime}(\mathrm{mm})$ and soil moisture weight percentage $M(\%)$ by the following formula:

$$
\left.Z^{\prime}=\mathrm{f} \times g^{M} \text { (where, } \mathrm{f} \text { and } \mathrm{g} \text { are constants. }\right)
$$

Based on the aforementioned results, the relation between small rectangular plate subsidence $Z(\mathrm{~mm})$ and index of hardness $X(\mathrm{~mm})$ can be explained as:

$$
X=-3.7 \times \ln (Z)+18.2
$$

Kanesu et al. (1966b) reported that the subsidence of a head-feeding combine's crawler and small rectangular plate subsidence $Z(\mathrm{~mm})$ were in proportion as expressed by:

$$
Z=\mathrm{h} \times Z^{\prime} \text { (where } \mathrm{h} \text { is constant.) }
$$

By substituting Formulas (2) and (4) to (3), we obtain

$$
X=-3.7 \times \ln (g) \times M+18.2-3.7 \times \ln (\mathrm{h} \times \mathrm{f})
$$

to verify the results of this study.

(2) Relation between index of hardness and fuel efficiency during traveling and driving

The relation between the driving force of a rubber crawler and the index of hardness of a road surface was studied, and Furuike et al. (2012) reported that the driving force was significantly effective when the index of hardness was $24 \mathrm{~mm}$ and below. An increase in driving force means increased resistance for traveling due to larger subsidence of the crawler into the soil, which ends up with an increase of fuel consumption. The report by Furuike et al. can therefore be considered as supporting the aforementioned result. 


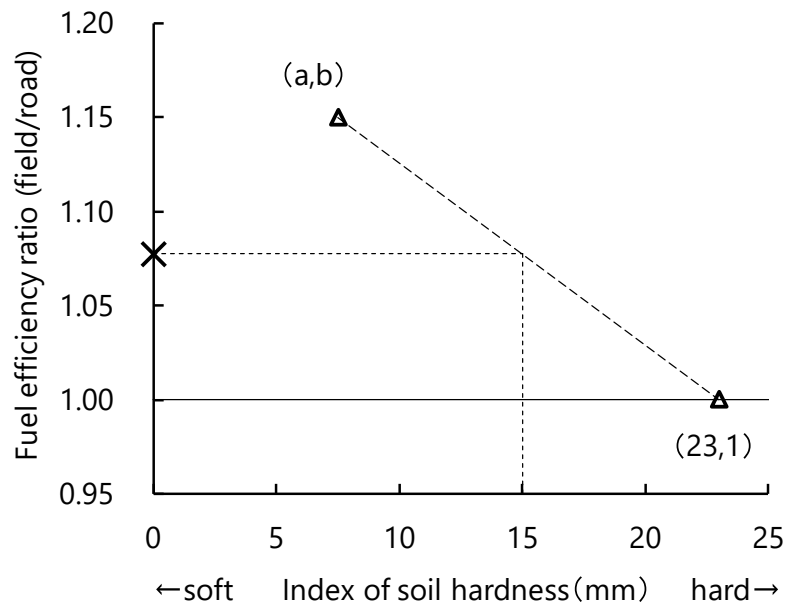

Fig. 10. Correction model of fuel efficiency during traveling and driving in accordance with soil conditions

Based on the results, Figure 10 shows a proposed correction model of fuel efficiency during traveling and driving in accordance with the soil conditions. We connected the plot $(23,1)$ at which the fuel efficiency ratio is equivalent to traveling on the road, and the plot (a, b) at which fuel efficiency was measured, in order to obtain a formula to explain the relation between index of hardness $X(\mathrm{~mm})$ using the provided machinery and fuel efficiency ratio $F E_{R}$.

$$
F E_{R}=\left\{\frac{(\mathrm{b}-1) X}{\mathrm{a}-23}\right\}+\left(\frac{\mathrm{a}-23 \mathrm{~b}}{\mathrm{a}-23}\right)
$$

In order to correct the impact of soil surface hardness, we calculate the fuel efficiency ratio under standard conditions by substituting $X=15$ in Formula (5), assuming that the index of hardness for surface soil hardness under standard conditions is $15 \mathrm{~mm}$.

\section{Impact of increased machinery body mass by the harvested crop relative to fuel efficiency during traveling and driving}

Based on the results, we propose the following correction method for fuel efficiency. By applying the fuel efficiency during traveling and driving in both empty and full grain tank status, along with grain mass $W_{F}(\mathrm{~kg})$ when the grain tank is full, we obtain coefficient $\varepsilon(1 / \mathrm{kg})$ to correct the impact of the grain mass on fuel efficiency during traveling and driving as shown in the formula below.

$$
\varepsilon=\frac{F E_{F}-F E_{E}}{F E_{E} \times W_{F}}
$$

where

$F E_{F}$ : fuel efficiency during traveling and driving; hourly

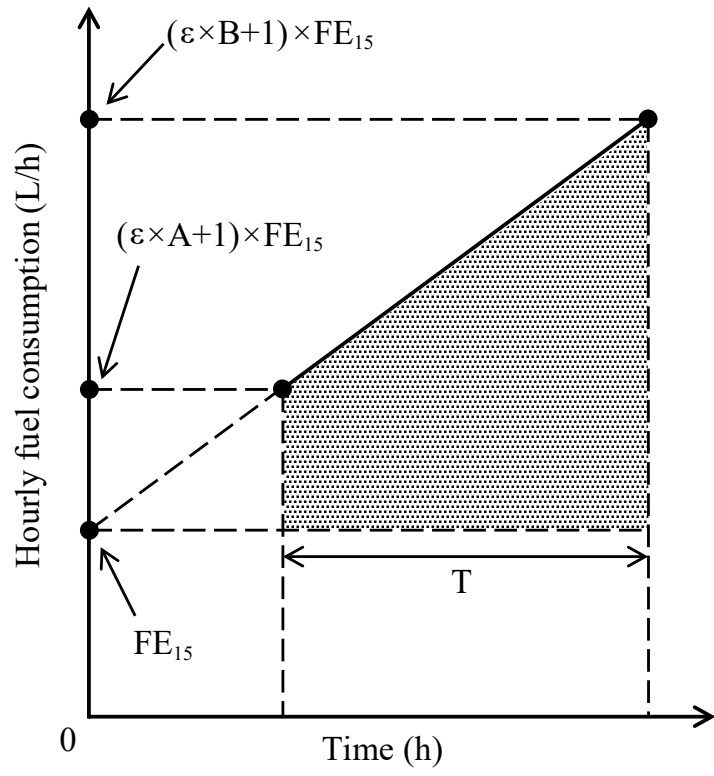

Fig. 11. Relation between working time and increase in hourly fuel consumption caused by an increase in grain mass

fuel consumption on a solid road when the grain tank is full $(\mathrm{L} / \mathrm{h})$.

$F E_{E}$ : fuel efficiency during traveling and driving; hourly fuel consumption on a solid road when the grain tank is empty $(\mathrm{L} / \mathrm{h})$.

Because $W_{F}$ varies depending on the characteristics of the harvested grain, testing should be conducted under grain conditions as heavy as possible. By using $\varepsilon$, the fuel efficiency during traveling and driving; hourly fuel consumption when the grain mass is $W(\mathrm{~kg}), F E_{W}(\mathrm{~L} / \mathrm{h})$ can be expressed by the formula below.

$$
F E_{W}=(\varepsilon \times W+1) \times F E_{15}
$$

where

$F E_{15}$ : fuel efficiency during traveling and driving; corrected hourly fuel consumption under the condition where the index of hardness is found to be $15 \mathrm{~mm}$ based on the results $(\mathrm{L} / \mathrm{h})$.

Due to the change of $W$ over time during harvest testing, $F E_{W}$ also changes at all times. We would thus obtain an additional amount of fuel consumption caused by an increase in grain mass, instead of correcting the fuel efficiency. When harvest work is carried out at any working speed in a field whose per area yield is stable, the increasing grain mass per unit time is stable, which also brings a stable increase in the fuel efficiency during traveling and driving caused by an increase in the mass of rough rice. Based on all these considerations, Figure 11 shows the relation between working time $T(\mathrm{~h})$ and an 
increase in the hourly fuel consumption caused by an increase in grain mass, during harvest work in which grain mass increased from $A(\mathrm{~kg})$ to $B(\mathrm{~kg})$. The additional amount of fuel consumption $F C_{P}(\mathrm{~L})$ due to an increase in grain mass is the same as the shaded area of the figure, and therefore can be expressed as:

$$
F C_{P}=(A+B) \times{ }_{\varepsilon} \times F E_{15} \times T \div 2
$$

We consider it desirable to show the amount of fuel consumption required to complete a certain area of harvesting work in evaluating the fuel efficiency of headfeeding combine harvesters because, unlike automobiles, fuel efficiency during harvest work changes over time.

As for "fuel efficiency during transport" that differs from "fuel efficiency during traveling and driving" only in terms of its working speed, the correction method that we clarified in this report shall be applicable, as the impact of surface soil hardness and grain mass on fuel efficiency can be considered in the same way. However, it was very difficult to quantify the work of a $90^{\circ}$ turn in case of "fuel efficiency during a $90^{\circ}$ turn" because there are many manipulation errors by the operator in the measured data. Although there may be some errors, we consider that "fuel efficiency during a $90^{\circ}$ turn" would be affected in the same degree as the fuel efficiency during traveling and driving due to soil surface hardness and an increase in self-weight by harvesting. Thus, it would be possible to demonstrate this conjecture, if the turning operation could be measured at the same turning speed, turning angle, and turning position without depending on the operator, as in the driverless combine harvester developed by Iida et al. (2006).

\section{Conclusion}

To determine the fuel efficiency during the traveling and driving of head-feeding combine harvesters, we conducted a study on the impacts of soil surface hardness and increased machinery body mass by the harvested crop, and devised a correction method so as to make a fair comparison among different models regardless of testing conditions.

Small rectangular plate subsidence (generally considered an index of soil conditions for harvesting tests of head-feeding combine harvesters) and the index of hardness are in a logarithmic relation, and we found that fluctuation of small rectangular plate subsidence on a hard soil field was limited despite of an increase in the index of hardness.

With regard to a decline of soil moisture weight percentage, we confirmed harder soil and an increase in the index of hardness, which suggested a strong correlation.

In response to a decline in the index of hardness, the fuel efficiency ratio tended to increase, and we noted a strong correlation between the index of hardness and the fuel efficiency ratio. The index of hardness realizing fuel efficiency equivalent to traveling on the road was about $23 \mathrm{~mm}$. Based on the fuel efficiency and the index of hardness obtained in the testing, we then figured out a relational expression between the index of hardness and fuel efficiency of the machinery provided for the testing, and thereby devised correction to the fuel efficiency during traveling and driving under any soil conditions.

And with regard to an increase in the grain mass, we confirmed an increase of the hourly fuel consumption. By using coefficient $\varepsilon(1 / \mathrm{kg})$ to correct the impact of grain mass relative to the fuel efficiency during traveling and driving, when the corrected hourly fuel consumption with a $15-\mathrm{mm}$ index of hardness is $F E_{15}(\mathrm{~L} / \mathrm{h})$, the grain mass before and after harvest work as $A$ and $B(\mathrm{~kg})$, respectively, and working time as $T(\mathrm{~h})$, the additional amount of fuel consumption $F C_{P}(\mathrm{~L})$ due to an increase in grain mass can be expressed by the formula below.

$$
F C_{P}=(A+B) \times{ }_{\varepsilon} \times F E_{15} \times T \div 2
$$

\section{Acknowledgments}

We would like to thank Dr. Nonami of Tottori University for assisting in the measurements. This research was conducted as part of the "Undertaking to Consider Promoting the Reduction of Carbon Dioxide Emissions in Agriculture," with the support of Japan's Ministry of Agriculture, Forestry and Fisheries (MAFF).

\section{References}

Baruah, D. C. et al. (2005a) Energy Requirement Model for a Combine Harvester, Part 1: Development of Component Models. Biosystems Engineering, 90, 9-25.

Baruah, D. C. et al. (2005b) Energy Requirement Model for Combine Harvester, Part 2: Integration of Component Models. Biosystems Engineering, 90, 161-171.

Commission for Standard Methods for Soil Analysis and Measurement (2003) Dojo Hyojun Bunseki Sokutei hou. Hakuyusha Co., Ltd. Tokyo, pp. 23-28 [In Japanese].

Ezaki, H. et al. (1982) Factor Analysis on the Relationship of Bearing Pressure and Sinkage Behaviours Using Model Track of Combine. Journal of JSAM, 43, 533-540 [In Japanese with English summary].

Iida, M. et al. (2006) Rice Harvest Using Driverless Combine Harvester Equipped with GPS and Gyro. Journal of JSAM, 68, 138-143 [In Japanese with English summary]. 
Japanese Society of Agricultural Machinery (1977a) Nougyou kikai shisetsu shiken houhou binran (I). JSAM, Tokyo [In Japanese].

Japanese Society of Agricultural Machinery (1977b) Nougyou kikai shisetsu shiken houhou binran (I). JSAM, Tokyo [In Japanese].

Japanese Society of Farm Work Research (1985) Shinpan Nousagyo Binran. JSFWR, Tokyo, pp. 418-419 [In Japanese].

JIS C8008-4 (2009) Reciprocating internal combustion enginesExhaust emission measurement- Part 4: Steady-state test cycles for different engine applications. Japanese Industrial Standards Committee.

JIS C8008-11 (2008) Reciprocating internal combustion engines -Exhaust emission measurement-Part 11: Test-bed measurement of gaseous and particulate exhaust emissions from engines used in nonroad mobile machinery under transient test conditions. Japanese Industrial Standards Committee.

Kanesu, M. et al. (1966a) Studies on Trafficability, Tractive and Rotary Tilling Performance of Tractor-Technical Report-.
Institute of Agricultural Machinery, Saitama, pp. 8-18 [In Japanese with English summary].

Kanesu, M. et al. (1966b) Studies on Trafficability, Tractive and Rotary Tilling Performance of Tractor-Technical Report-. Institute of Agricultural Machinery, Saitama, pp. 25-31 [In Japanese with English summary].

Koike, R. et al. (2012) Driving force of rubber track and soil hardness of road surface. Journal of The Japan Forest Engineering Society, 27, 119-122 [In Japanese].

Sakai, N. et al. (1988) The Required Energy in Harvesting for Grains and Soybean. Journal of JSFWR, 23, 94-103 [In Japanese with English summary].

Seki, E. et al. (2006) Evaluation of Exhaust Gas Emission for Agricultural Tractors Based on Actual Operations. Journal of JSAM, 68, 130-137 [In Japanese with English summary].

Suzuki, M. (1980) Performance of Rice Combine Harvesters as Evaluated by the National Test in Japan. JARQ, 14, 20-23.

Yamanaka, K. et al. (1962) Studies on Soil Hardness (Part 1): On the Soil Hardness Tester. Japanese Society of Soil Science and Plant Nutrition, 33, 343-347 [In Japanese]. 